\title{
Hybridization and Introgression Between the Endemic Phoenix canariensis and the Introduced $P$. dactylifera in the Canary Islands
}

\author{
M.A. González-Pérez and P.A. Sosa* \\ Departamento de Biología, Universidad de Las Palmas de Gran Canaria, 35017 Las Palmas, Canary Islands, Spain
}

\begin{abstract}
The proportion of hybridization and introgression between the endemic Phoenix canariensis (Canarian date palm) and the introduced $P$. dactylifera (date palm), were characterized using a multilocus isozyme genotype, based on 17 isozyme loci. In order to evaluate the multilocus isozyme genotype's ability to detect hybridization and introgression between the endemic Phoenix canariensis and the introduced P. dactylifera, multilocus genotype data from pure and putative hybrid populations were analyzed with a Bayesian-based method, implemented in the STRUCTURE software. The identity of all Phoenix canariensis plants was confirmed. However, in the putative P. dactylifera individuals examined, some of them were designated as hybrid, and others as Canarian date palms. Individuals from each species were clustered separately, while putative hybrid individuals shared ancestors from clusters where both Phoenix species were assigned. In agreement with this, FCA showed that the hybrids were localized between $P$. canariensis and $P$. dactylifera individuals' clouds, but with a closer proximity to the former, suggesting an introgression from Phoenix dactylifera to $P$. canariensis. In addition, the Bayesian cluster revealed a geographical structure within $P$. canariensis relative to island origin, so populations from the western islands of the archipelago were clustered together and separately from eastern islands.
\end{abstract}

Keywords: Multilocus genotype, allozymes, Canary Islands, conservation genetics, hybridization, Phoenix canariensis, Phoenix dactylifera, introgression, bayesian analysis.

\section{INTRODUCTION}

Invasive species are recognized as the second largest threat to biodiversity after habitat loss [1] and they have therefore become a major risk to the health of ecosystems worldwide [2] and a key focus for wildlife management agencies [3]. However, the control of invasive species is often hampered by a lack of information about the history and origins of the population in question and to what level of connectivity exists between groups of individuals. In addition, the control of an invasive species becomes more difficult when hybridization between the introduced species and the native one occurs in nature. Inter-specific hybridization is a common natural phenomenon of evolutionary importance [4]; however, unnatural mixing of historically isolated taxa due to human-related activities has increased dramatically in recent decades [5]. Hence, the accurate detection of hybrid individuals has a range of conservational applications [6].

Introgression is the incorporation of a gene (gene flow) from one species into the gene pool of another as a result of inter-specific hybridization. The harmful effects of hybridization, with or without introgression, have led to the extinction of many populations and species in many plant and animal taxa. Hybridization is especially problematic for rare species that come into contact with other species that are more abundant [7]. Backcrossing of hybrid individuals to the

*Address correspondence to this author at the Departamento de Biología, Universidad de Las Palmas de Gran Canaria, 35017 Las Palmas, Canary Islands, Spain; Tel: +34.928.45.45.43; Fax: +34.928.45.29.22;

E-mail: psosa@dbio.ulpgc.es abundant parental population may eventually result in the extinction of the endangered species through hybridization [8]. The key to preventing introgression in populations of endangered species is the efficient detection and removal of hybrids [9].

Assessment of inter-specific hybridization and introgression between species or subspecies is important for the implementation of appropriate genetic conservation strategies. An efficient management of natural genetic resources needs to identify and conserve the remaining unique populations and to evaluate the extent to which they are endangered by the introduction of alien species $[10,11]$, that pose a clear threat to the genetic integrity of the endemic populations through hybridization and eventual outbreeding depression.

The detection of hybrids using morphological characters generally assumes that hybrid individuals will be phenotypically intermediate to a parent's individuals. This is often not the case, because hybrids sometimes express a mosaic of parental phenotypes [7, 12, 13]. Furthermore, individuals from a hybrid swarm that contain most of their genes from one of the parental taxa are often morphologically indistinguishable from those parental taxa. In addition, morphological characters do not allow one to determine whether an individual is a first generation hybrid $\left(\mathrm{F}_{1}\right)$, a backcross, or a late generation hybrid [7].

Genetic methods can provide vital information regarding the origins and order of introductions, identity population structure and estimate the dispersal between groups of individuals [14]. One of the major advances in the genetic conservation field has been the development of numerous 
new statistical methods. Indeed, a solution to the problem of detecting hybridization and hybrid individuals in contact zones of populations or species may be provided by recent model-based Bayesian statistical techniques. These methods have already been utilized for identifying potential hybridization or hybrid individuals in a wide range of scenarios [15-20] and for identifying hybrid zones [21] or introgression [22].

Phoenix canariensis Hort. ex Chabaud is an endemic palm species from the Canary Islands that co-occurs with its widespread congener Phoenix dactylifera L. in many stands as a consequence of the artificial introduction of the latter. $P$. dactylifera was introduced by the Canarian farmers for use and enhanced exploitation [23]. Nowadays, both species are planted for ornamental reasons in the entire world, including in the Canary Islands. Archaeological evidences, based on the presence of Phoenix canariensis seeds in archaeological sites, and not $P$. dactylifera, suggest that Phoenix dactylifera was introduced after Spanish conquest [24], that means, only about 500 years ago. However, the lack of historical records and the ad hoc nature of these introductions make it difficult to determine the degree and distribution of introduction.

Interspecific hybridization is relatively common in the Phoenix species $[25,26]$. In this sense, the endemic, Phoenix canariensis, and the widespread, $P$. dactylifera, have been known to hybridize in various anthropogenic contexts where both species are brought into proximity [27, 28]. The distinction of $P$. canariensis from $P$. dactylifera is at present based solely on morphological traits [29]. However, morphological characterization has been ineffective for the right ascription to the taxon of individuals from both species and its putative hybrids, mainly in the hybrid zone [29], with almost no reliable characters available to distinguish other Phoenix species [25]. Thus, it is necessary to use a marker to unravel genetic differentiation between both species. Canarian palm populations are catalogued as priority habitats by Nature 2000 of the European Union, catalogued as a forest species and it has been chosen as the Floral Symbol of the Canarian archipielago by the Canary Government.

An isozyme analysis carried out [30] did not find a diagnostic loci able to discriminate unambiguously $P$. canariensis and $P$. dactylifera from their putative hybrids, since both, $P$. canariensis and $P$. dactylifera, shared some alleles, indicating recent divergence of both taxons [29,30]. However, these same authors [31] described a molecular marker (RAPD) able to differentiate both Phoenix species, as well as its putative hybrids. However, backcross could eliminate these markers, so that $F_{2}$ and posterior hybrid generations could be undetected by these markers. In this sense, managers sometimes note that a certain proportion of individuals in a hybrid swarm only have alleles that are characteristic of the native taxon at the diagnostic loci analyzed, and they mistakenly interpret these to be pure individuals. This interpretation is not correct, because, in a hybrid swarm, the genes of the parental taxa are randomly distributed among the individuals in the population [7]. So, we should be cautious in the inferences about introgression based on specific diagnostic molecular markers, such as RAPD [31], since introgression could be higher than those detected in this analysis. However, the use of the Bayesian cluster analysis based on multilocus genotypes could help to identify inter-specific hybridization and introgression between the endemic $P$. canariensis and the introduced $P$. dactylifera, since it has been used for identifying interspecific hybridization and introgression between other species [19, 22].

On the whole, inter-specific mating between a endemic species and a common one will have one of two consequences relevant to conservation biology [32]: i) if hybrid progeny and progeny from advanced hybridization are vigorous and fertile, the endemic species is at risk from genetic assimilation; ii) if hybrid progeny are sterile or have reduced vigor, then the species is at risk from outbreeding depression. Therefore, the lack of knowledge about the nature, origin and purity of the $P$. canariensis populations, as well as the degree of introgression of $P$. dactylifera, has stood in the way of the conservation efforts for this Canarian endemic.

The goals of this study were 1) to evaluate the multilocus isozyme genotype's ability to detect hybridization between the endemic Phoenix canariensis and the widespread $P$. dactylifera in the Canary Islands, 2) to characterize patterns of natural hybridization and introgression between $P$. canariensis and $P$. dactylifera in the Canaries, and to evaluate their evolutionary consequences.

\section{MATERIALS AND METHODS}

\section{Plant Material}

A total of 649 individuals belonging to 20 populations (Table 1, Fig. 1). Those populations that were classified according to González-Pérez [29, 30, 31], as: i) natural populations of $P$. canariensis; ii) $P$. dactylifera populations; and iii) mixed stands, whose contained individuals of $P$. canariensis, $P$. dactylifera and a continuous range of morphologically intermediate plants.

\section{Isozyme Data}

Isozyme data from previous studies $[29,30]$ were used in order to carry out genotype multilocus analysis. This allowed the interpretation of 17 putative loci (13 polymorphic), which were used.

\section{Data Analysis}

Tests for assignment of individuals to species and the estimation of admixture from multilocus genotype data were carried out using a Bayesian-based method, implemented in STRUCTURE [33]. This Bayesian cluster analysis identifies the $K$ (unknown) populations of origin of the sampled individuals and assigns the individuals simultaneously to the populations. The most likely value of $K$ is assessed by comparing the likelihood of the data for different values of $K$. We assumed the model to be of population admixture and that the allele frequencies are independent. We conducted a series of independent runs for each value of $K$ (the number of subpopulations) between 2 and 21. Analyses consisted of $10^{5}$ burn-in period replicated and a run length of $10^{6}$ replicates.

Populations and individuals were assigned to one cluster if their proportion of membership (qi) to that cluster was 
Table 1. Phoenix Populations Analysed and Bayesian Clustering Analysis Showing the Proportion of Membership $\left(q_{i}\right)$ of Each Predefined Sampled Population in Each of Three Inferred Clusters. N: Sample Size. MC: Morphological Characterization, PC: Phoenix canariensis, PD: Phoenix dactylifera, MHs: Mixed/Hybrid Stand

\begin{tabular}{|c|c|c|c|c|c|c|c|}
\hline \multirow{2}{*}{ Locality } & \multirow{2}{*}{ Population } & \multirow{2}{*}{ Code } & \multirow{2}{*}{$\mathbf{N}$} & \multirow{2}{*}{ MC } & \multicolumn{3}{|c|}{ Cluster } \\
\hline & & & & & I & II & III \\
\hline \multirow{8}{*}{ Gran Canaria } & AcusaVerde & $\mathrm{AC}$ & 25 & $\mathrm{PC}$ & 0.717 & 0.268 & 0.015 \\
\hline & Bco. Angostura & $\mathrm{BA}$ & 21 & MHs & 0.826 & 0.150 & 0.024 \\
\hline & Tafira & TA & 46 & MHs & 0.762 & 0.196 & 0.042 \\
\hline & Fataga & TI & 41 & MHs & 0.865 & 0.097 & 0.038 \\
\hline & Hospital Materno & $\mathrm{HM}$ & 10 & PD & 0.089 & 0.036 & 0.875 \\
\hline & La Sorrueda & LS & 45 & $\mathrm{PC}$ & 0.876 & 0.116 & 0.008 \\
\hline & Maspalomas & SB & 35 & MHs & 0.550 & 0.161 & 0.289 \\
\hline & Pasito Blanco & PB & 27 & $\mathrm{PD}$ & 0.025 & 0.017 & 0.958 \\
\hline \multirow{2}{*}{ Fuerteventura } & Gran Tarajal & GT & 42 & $\mathrm{PD}$ & 0.100 & 0.082 & 0.817 \\
\hline & Río Palma & RP & 38 & MHs & 0.895 & 0.025 & 0.079 \\
\hline \multirow{2}{*}{ Lanzarote } & Haría & HA & 42 & MHs & 0.501 & 0.449 & 0.050 \\
\hline & Maguez & MA & 34 & MHs & 0.436 & 0.416 & 0.148 \\
\hline \multirow{2}{*}{ Tenerife } & A. Culata & $\mathrm{ACN}$ & 10 & $\mathrm{PC}$ & 0.466 & 0.525 & 0.009 \\
\hline & Rambla Castro & $\mathrm{RC}$ & 24 & $\mathrm{PC}$ & 0.333 & 0.576 & 0.090 \\
\hline \multirow{3}{*}{ La Gomera } & Las Hayas & HY & 40 & $\mathrm{PC}$ & 0.023 & 0.963 & 0.014 \\
\hline & Tamargada & TAM & 41 & $\mathrm{PC}$ & 0.145 & 0.846 & 0.009 \\
\hline & Vegaipala & VP & 41 & $\mathrm{PC}$ & 0.010 & 0.979 & 0.011 \\
\hline \multirow{2}{*}{ La Palma } & Mirca & MI & 27 & $\mathrm{PC}$ & 0.463 & 0.524 & 0.013 \\
\hline & El Zumacal & $\mathrm{ZU}$ & 22 & $\mathrm{PC}$ & 0.163 & 0.818 & 0.019 \\
\hline Elche & Elche & EL & 40 & PD & 0.017 & 0.021 & 0.962 \\
\hline
\end{tabular}

equal to or larger than the arbitrary threshold of 0.800 . Two multivariate representations of individuals analyzed were carried out by subjecting individual allelic data to Factorial Correspondence Analysis (FCA) in Genetix version 4.02 [34]. One of the multivariate representations followed the morphological characterization, whereas the other followed the Bayesian cluster analysis assignation of the individuals.

\section{RESULTS}

Bayesian analysis, using the total data set (649 individuals, 17 allozyme loci, 20 sampled populations) and $K$ $=2$ to 21 , showed that the probability of the data was maximum, with $K=20$, suggesting the presence of additional levels of structure in the total sample (Fig. 2a). Choosing a value of $K$ that maximizes the posterior probability of the data (PPD) can be difficult to apply for complex data sets including many groups [35]. In the case of highly structured data, as $K$ is increased the most divergent groups separate first into distinct clusters. Since the aim should be to find the smallest value of $K$ that captures the major structure in the data, a second way to choose $K$ is to consider the successive increase of the PPD for increasing values of $K$, which can be regarded as the increase in information at each addition of a set of allele frequencies. The increase of the PPD was high for $K=3$, but for $K>3$ the increase in information became markedly less and showed gradually decreasing values (Fig. 2b). This result means that the information obtained by the three clusters (and the subsequent clusters) was much less important than the information obtained by the former two. Once two populations had been assigned to different clusters for $K=3$, they never belonged to the same cluster for greater values of $K$, and the individuals were assigned asymmetrically to each group. But what do these three inferred groups correspond to? The genetic contributions of each inferred group into the individual genotypes is depicted in the insets of Fig. (1). Bayesian clustering analysis indicated three distinct genetic clusters (Table 1). Predefined populations assigned to the third group included all the $P$. dactylifera populations, while first and second clusters included all the $P$. canariensis populations. On the other hand, most populations assigned to cluster II belong to the Western islands (Tenerife, La Palma and La Gomera). While most populations from the Eastern islands (Gran Canaria, Fuerteventura and Lanzarote) were included in cluster I (Table 1).

In regard to mixed stands, three of them (BA, FA and RP) were assigned to cluster I, while TA, MAS, HA and MAG were not assigned to any single cluster with $q_{i} \geq 0.800$, but they were split into cluster I and/or II and cluster III (Table 1). In spite of this, MAS population is the mixed stand with a higher proportion of membership in cluster III. However, only one individual of this population can be attributed to this cluster with a $\mathrm{q} i \geq 0.800$ (Table 1 ). A FCA of individual genotypes based on morphological characterization was unable to separate $P$. canariensis and $P$. dactylifera individuals or its putative hybrids (Fig. 3a). However, a FCA of individual genotypes following Bayesian analysis assignation implemented in STRUCTURE software [33], separated the two species into two distinct clouds according to axis 1 (Fig. 3b). While $P$. canariensis individuals were very close to one another in the spatial analysis, date palms individuals were more scattered. Putative hybrids recognized through a Bayesian analysis method were localized between both points' clouds corresponding to each species, although most were closely integrated within $P$. canariensis (Fig. 3b).

\section{DISCUSSION}

The isozyme multilocus analysis used in this study separated both Phoenix species, as well as, mixed/hybrid stands. The Bayesian cluster analysis strongly supported genotype differentiation between both Phoenix species, since individuals from $P$. canariensis populations and $P$. dactylifera populations were assigned to different clusters. Individuals from $P$. canariensis were assigned to cluster I and cluster II, while individuals from $P$. dactylifera populations were assigned to cluster III. Also, individuals from mixed stands were attributed to any cluster. Within the $P$. canariensis species, those populations from Western islands (Tenerife, Gomera and La Palma) were mainly assigned to cluster II, while populations from Eastern islands 


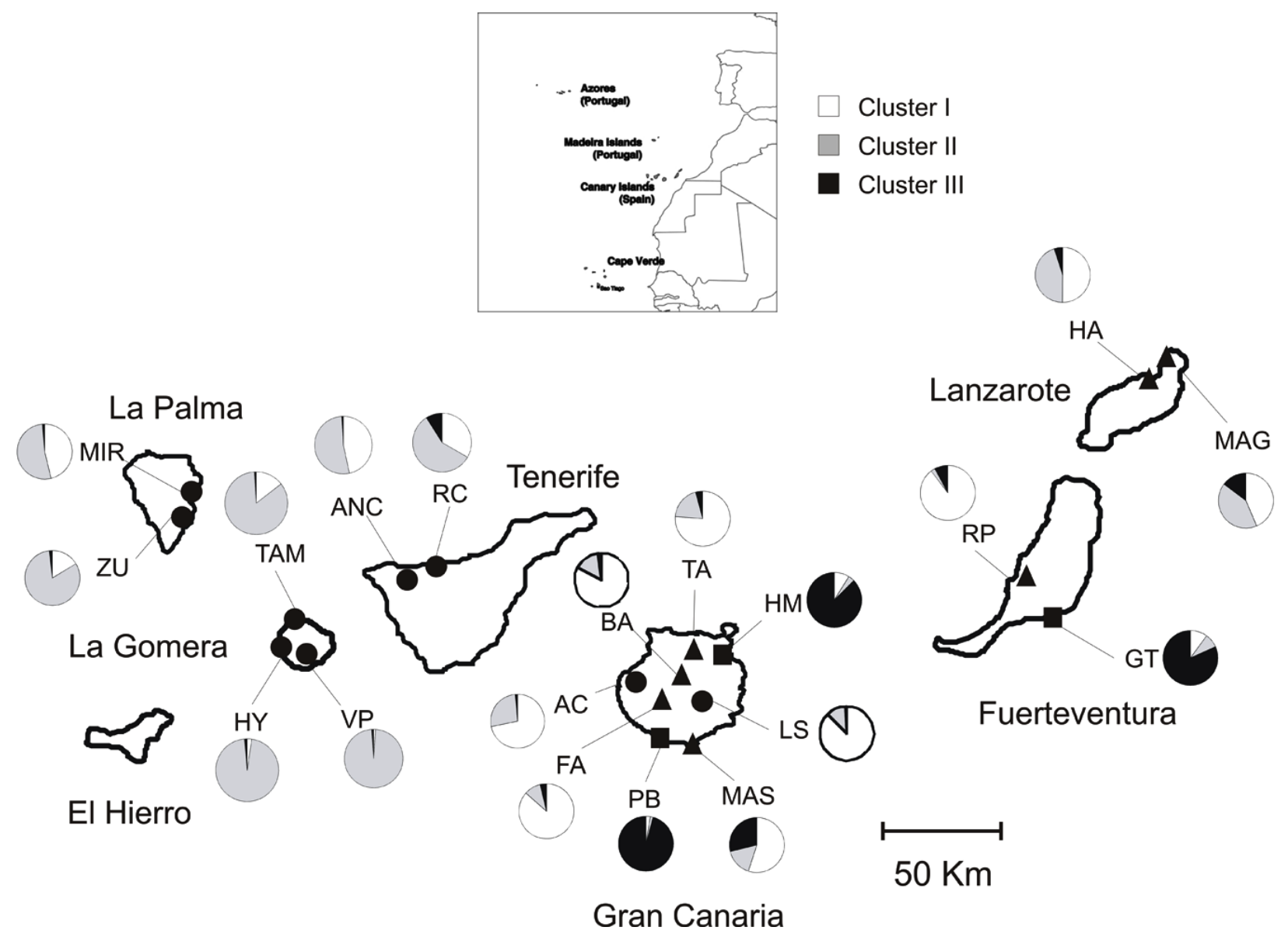

Fig. (1). Populations sampled of Phoenix canariensis ( $\bullet$ ), Phoenix dactylifera $(\boldsymbol{\square})$ and mixed populations $(\boldsymbol{\Delta})$ in the Canary Islands. Population codes are as in Table 1. Insects: the estimated genetic contribution of the inferred groups into the individual genotypes (see results).

(Gran Canaria, Fuerteventura and Lanzarote) were mainly assigned to cluster I, suggesting a geographical structure related to the islands, except for a group of individuals from Lanzarote (eastern island). However, we must consider the possible artificial origin of these populations from Lanzarote $[30,36]$, since both populations had not been described in the island until the $18^{\text {th }}$ century, even though there had been botanic reports about the island vegetation since 1402 [36]. In addition, the movement of palms within and between islands has been a common occurrence [37]. Besides, Bayesian cluster analyses suggest an intra-specific gene flow between islands, since populations from Eastern and Western islands share the same two ancestors (clusters), although with different proportions. So, we suggest that there are possibly historical and therefore a genetic relationship [30] between both populations from Lanzarote and the western islands of the archipelago. The existence of genetic differences in populations localized in different islands is a common process detected in oceanic islands, and specifically in the Canarian archipelago [38-40].

Bayesian cluster analysis revealed by STRUCTURE software showed individuals that could be considered as hybrid, since it presented mixed ancestry (cluster I or II and cluster III). On the whole, a total of 59 individuals $(9 \%)$ were characterised as hybrid by multilocus genotype in the populations analyzed. These individuals showed a shared proportion of membership $\left(\mathrm{q}_{\mathrm{i}}\right)$ between cluster III and cluster I and/or cluster II, in a range between $0.4<\mathrm{q}_{\mathrm{i}}<0.6$, and had a similar probability of assignment to either $P$. canariensis or $P$. dactylifera, which was interpreted as mixed ancestry. Most of these individuals $(76.27 \%)$ were localized in mixed stands. However, the hybrid presence in mixed stands was lower than expected, in fact only a 18\% (44 individuals) were recognized as hybrid (21 from MAS population, 10 from MAG, 5 from RP, 3 from TA and HA, and 2 from FA).

On the other hand, the number of $P$. dactylifera individuals in mixed stands was lower than expected, because only one individual from the Maspalomas population was clustered with $P$. dactylifera individuals from date palms populations. This is in agreement with previous RAPD analysis [31], where $P$. dactylifera individuals were only detected in the mixed stands of the Maspalomas populations. These results show that the morphological characterization can cause mistakes in the identification of the Canarian palm, especially in those mixed stands where introgression and hybridization have probably occurred.

In this sense, FCA analysis based on morphological characterization of Phoenix individuals was unable to separate individuals from both species (Fig. 3a). In fact, many individuals morphologically characterized as pure Phoenix dactylifera or $P$. canariensis, mainly in the mixed 
A)

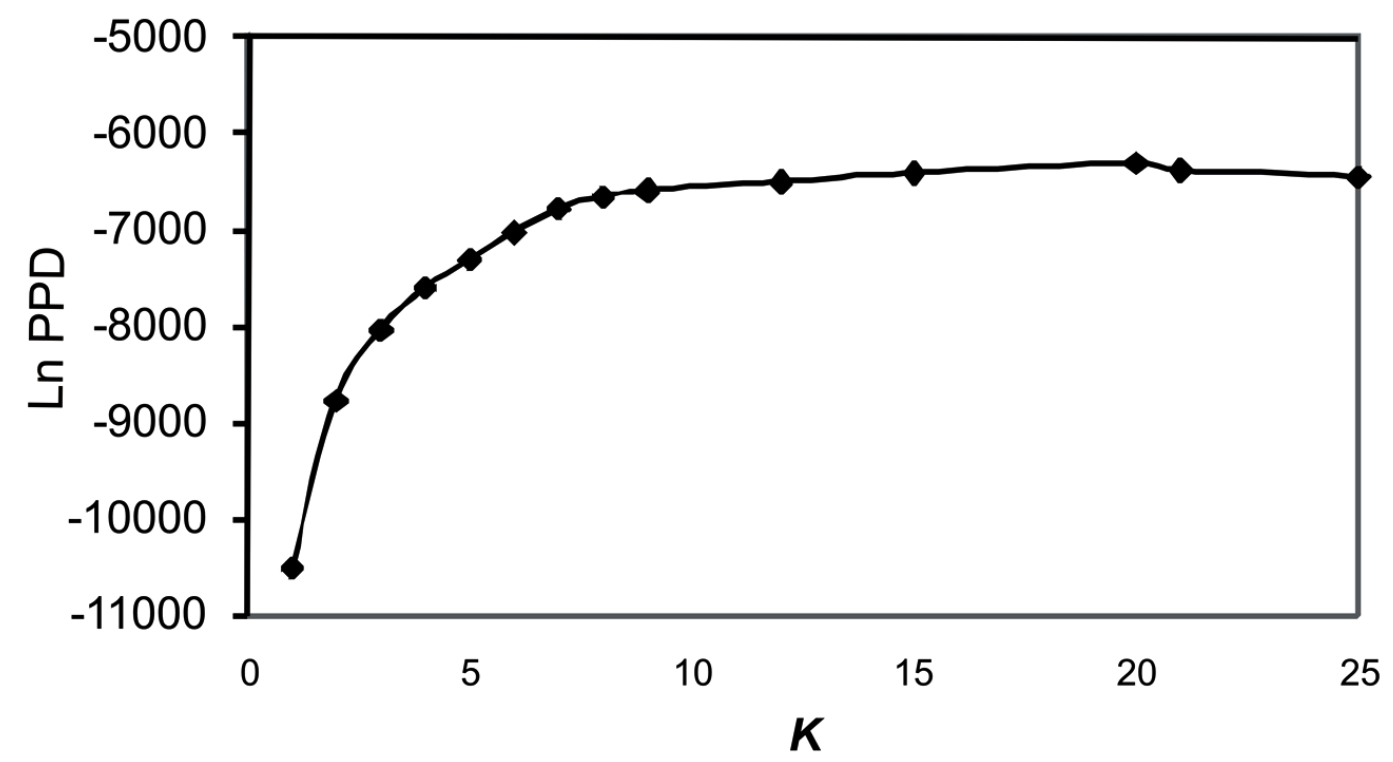

B)

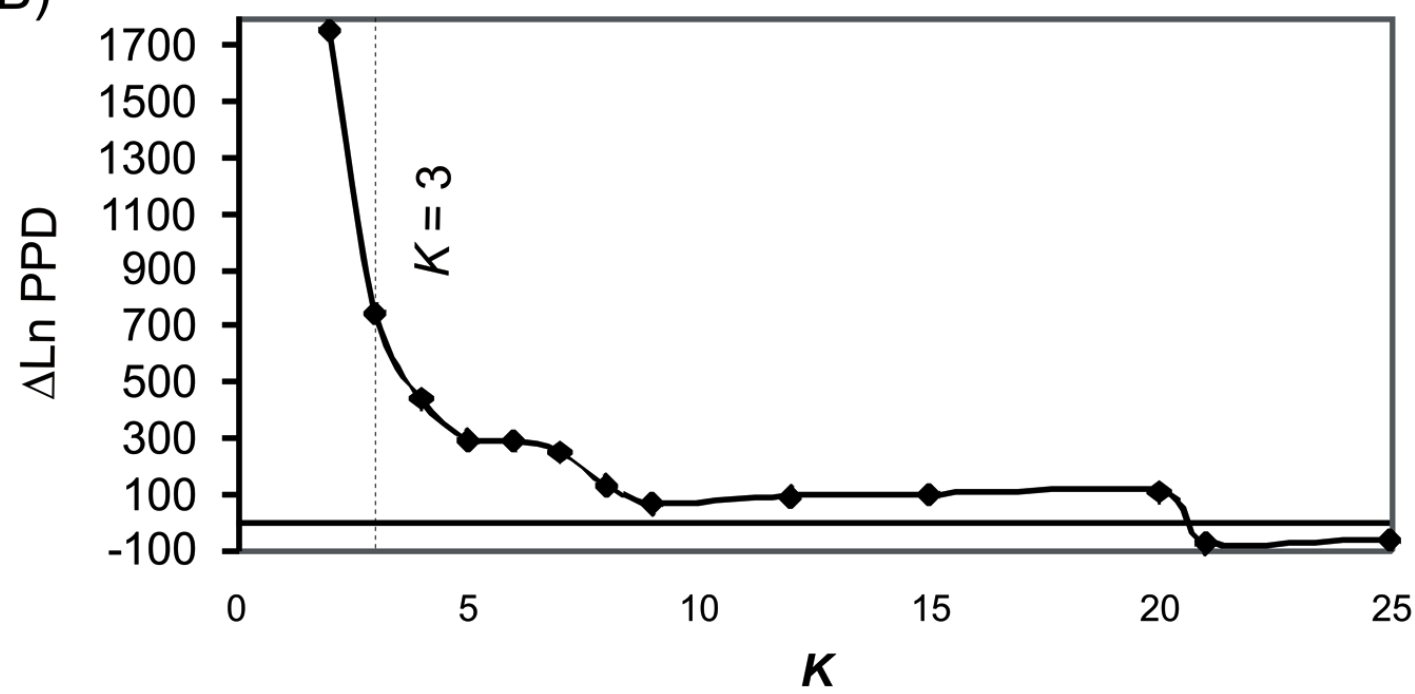

Fig. (2). Posterior probability of the data (PPD) against the maximum number of clusters (K) considered (A), increase of PPD given K (B). For K clusters, this increase is calculated as (Ln PPDK - Ln PPDK-1).

stands, were later revealed to be hybrid in the genetic analysis, and vice versa. However, FCA analysis following a Bayesian analysis assignation formed two perfectly distinct clouds (Fig. 3b). This clear-cut separation is remarkable given that, as previously mentioned, no diagnostic loci could be found in the studied set of enzymes [30]. Interestingly, the putative hybrids are located between the two clouds. Although, most hybrids were localized closer to the $P$. canariensis individuals cloud, indicating that gene flow occurs between a hybrid and one or the other individual of the parental species, then the segregating generations will be mostly advanced backcrosses and have multilocus associations typical of the most compatible parents [41]. The fact that $P$. canariensis individuals were clustered closer and $P$. dactylifera individuals were more dispersed in the spatial representation (FCA), suggests that $P$. dactylifera populations are genetically more diverse than $P$. canariensis populations. These results coincide with those described by different authors $[25,31]$. 


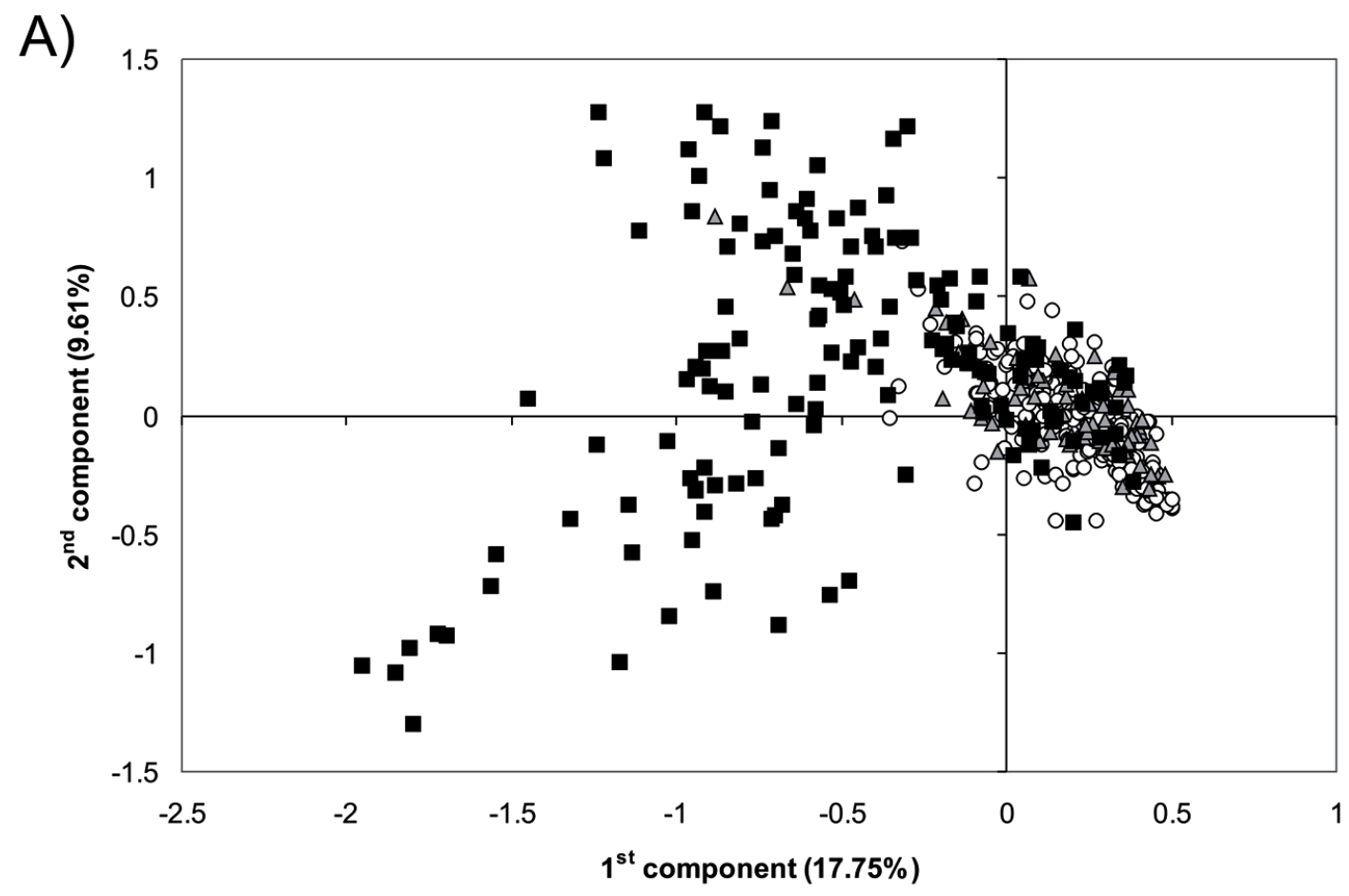

B)

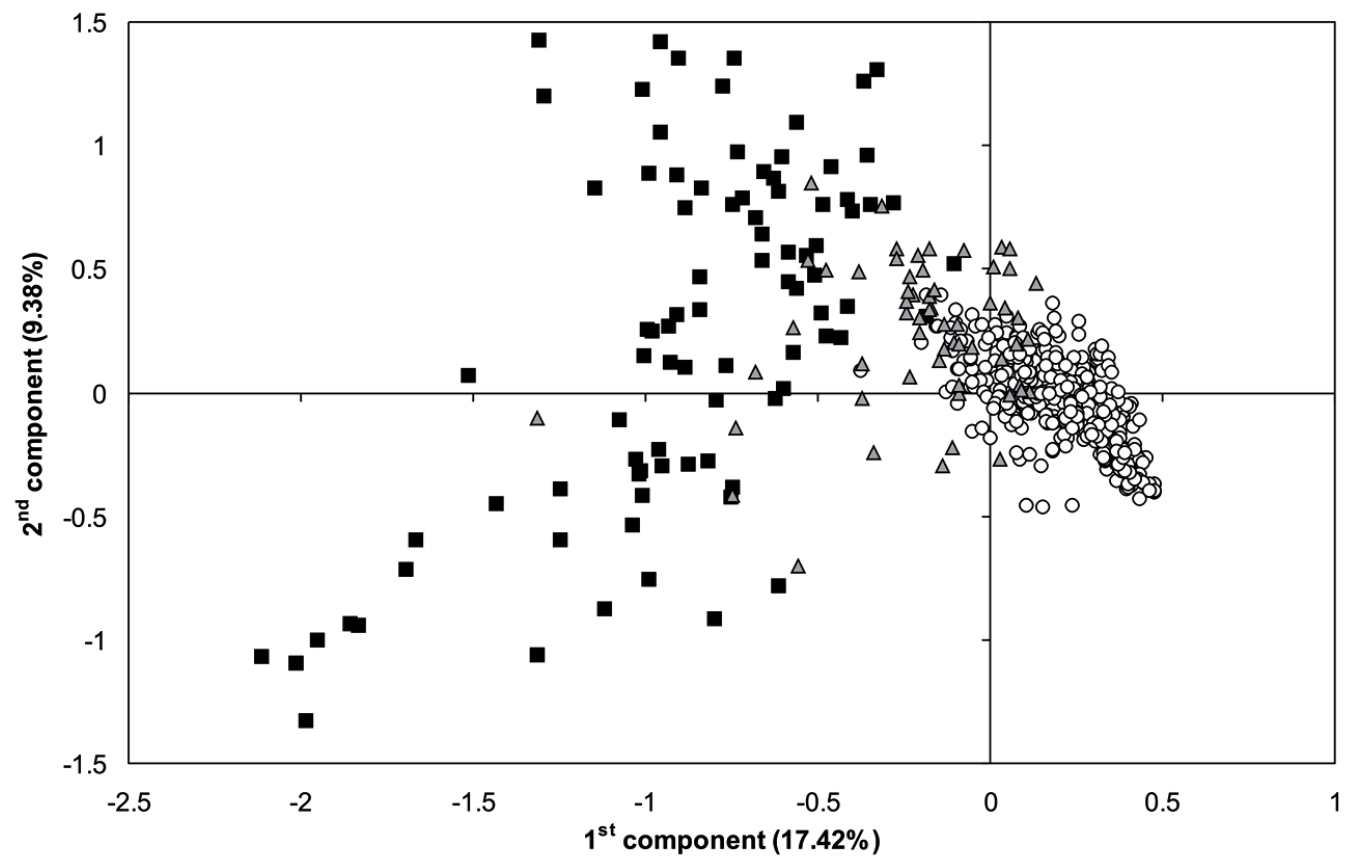

Fig. (3). Factorial correspondence analysis of the individual isozyme allelic data analysis of 649 P. canariensis and $P$. dactylifera individuals from the Canary islands. (O) Phoenix canariensis, ( $)$ Phoenix dactylifera, and ( $\triangle$ ) Hybrid following morphological characterization (A) and Bayesian-method analysis assignation $(\mathbf{B})$ implemented in STRUCTURE software [25].

The existence of hybrid swarms makes conservation and recovery of threatened taxa much more difficult. In the case of $P$. canariensis, hybridization might have begun only recently or might be geographically restricted so that parental populations still exist, but if conservation actions are not taken, all populations could become hybrid swarms (complete admixture) [7]. Molecular markers such as isoenzymes [30], RAPD [31] or microsatellites [25, 26] have shown themselves to be useful tools to identify the degree of introgression and hybridization of the foreign palm in the Canary Islands. 


\section{CONCLUSIONS}

In summary, we can conclude that inter-specific hybridization and introgression between the endemic Phoenix canariensis and the introduced $P$. dactylifera has occurred. This hybridization could be identified as type 5 (widespread introgression) following the hybrid categorization designed by Allendorf et al. [7]. Type 5 hybridization is an anthropogenic hybridization, where hybridized populations are of little conservation value (although they could have other values). Although, introgression in the mixed stands seem to be lower than expected, genetic monitoring of these populations can provide essential information to managers, and efforts should focus on maintaining and expanding the remaining pure populations. On the other hand, intra-specific gene flow is a relevant factor in the detected patterns, since populations from different islands share a part of their genetic pool.

\section{REFERENCES}

[1] Lowe S, Browne M, Boudjelas S, De Poorter M. 100 of the world's worst invasive alien species. Aliens 2000; 12: 12-3.

[2] Duncan RP, Blackburn TM, Sol D. The ecology of bird introductions. Annu Rev Ecol Syst 2003; 34: 71-98.

[3] Leung B, Lodge DM, Finnoff D, Jason FS, Lewis MA, Lamberti G. An ounce of prevention or a pound of cure: bioeconomic risk analysis of invasive species. Proc R Soc B 2002; 269: 2407-13.

[4] Barton NH. The role of hybridization in evolution. Mol Ecol 2001; 10: 551-68.

[5] Olden Jd, LeRoy PN, Douglas MR, Douglas ME, Fausch KD. Ecological and evolutionary consequences of biotic homogenization. Trends Ecol Evol 2004; 19: 18-24.

[6] Vilà C, Walker C, Sundqvist AK, et al. Combined use of maternal, paternal and bi-parental genetic markers for the identification of wolf-dog hybrids. Heredity 2003; 90: 17-24.

[7] Allendorf FW, Leary RB, Spruell P, Wenburg JK. The problems with hybrids: setting conservation guidelines. Trends Ecol Evol 2001; 16: 613-22.

[8] Rhymer JM, Simberloff D. Extinction by hybridization and introgression. Annu Rev Ecol Syst 1996; 27: 83-109.

[9] Miller CR, Adams JR, Waits LP. Pedigree-based assignment tests for reversing coyote (Canis Latrans) introgression into the wild red wolf (Canis rufus) population. Mol Ecol 2003; 12: 3287-301.

[10] Novak SJ, Mack RN. Genetic variation in Bromus tectorum (Poaceae): Comparison between native and introduced populations. Heredity 1993; 71: 167-76.

[11] Largiadèr CR, Scholl A. Genetic introgression between native and introduced brown trout (Salmo trutta $\mathrm{L}$.) populations in The Rhône River Basin. Mol Ecol 1996; 5: 417-26.

[12] Campton DE. Natural hybridization and introgression in fishes: methods of detection and genetic interpretations. In: Ryman N, Utter F, Eds. Population Genetics and Fishery Management. University of Washington Press 2000: 161-92.

[13] Smith GR. Introgression in fishes-significance for paleontology, cladistics, and evolutionary rates. Syst Bot 1992; 41: 41-57.

[14] Rollins LA, Woonlnough AP, Wilton AN, Sinclairs R, Sherwin WB. Invasive species can't cover their tracks: using microsatellites to assist management of starling (Sturnus vulgaris) populations in Western Australia. Mol Ecol 2009; 18: 1560-73.

[15] Hansen MM. Estimating the long-term effects of stocking domesticated trout into wild brown trout (Salmo trutta) populations: an approach using microsatellite DNA analysis of historical and contemporany samples. Mol Ecol 2002; 11: 1003-15.

[16] Pierpaoli M, Biro ZS, Hermann M. Genetic distinction of wildcat (Felis silvestres) populations in Europe, and hybridization with domestic cats in Hungary. Mol Ecol 2003; 12: 2585-98.

[17] Cianchi R, Ungaro A, Marini M, Bullini L. Differential patterns of hybridization and introgression between the swallowtails Papilio machaon and $P$. hospiton from Sardinia and Corsica islands (Lepidoptera, Papilionidae). Mol Ecol 2003; 12: 1461-71.

[18] Viard F, Arnaud JF, Delescluse M, Cuguen J. Tracing back seed and pollen flow within the crop-wild Beta vulgaris complex: genetic distinctiveness $v s$ hot spots of hybridization over a regional scale. Mol Ecol 2004; 13: 1357-64.

[19] Andersson AC, Narain Y, Tegelström H, Fredga K. No apparent reduction of gene flow in a hybrid zone between the West and North European karyotypic groups of the common shrew, Sorex araneus. Mol Ecol 2004; 13: 1205-15.

[20] Lucchini V, Galov A, Randi E. Evidence of genetic distinction and long-term population decline in wolves (Canis lupus) in the Italian Apennines. Mol Ecol 2004; 13: 523-36.

[21] Nielsen EE, Hansen MM, Ruzzante DE, Meldrup D, Grønkjær P. Evidence of a hybrid-zone in Atlantic cod (Gadus morhua) in the baltic and the Danish Belt Sea revealed by individual admixture analysis. Mol Ecol 2003; 12: 1497-508.

[22] Susnik S, Berrebi P, Dov P, Hansen MM, Snoj A. Genetic introgression between wild and stocked salmonids and the prospects for using molecular markers in population rehabilitation: the case of the Adriatic grayling (Thymallus thymallus L. 1785). Heredity 2004; 93: 273-82.

[23] Santana SA, Toledo RJM. Introducción y dispersión de Phoenix dactylifera en el archipiélago canario: elementos de discusión. In: Second International Symposium on Ornamental Palms and other Monocts from the Tropics; Puerto de la Cruz, Spain 1997.

[24] Morales J. La explotación de los recursos vegetales en la prehistoria de las Islas Canarias. Una aproximación carpológica a la economía, ecología y sociedad de los habitantes prehispánicos de Gran Canaria. Ph. D thesis, University of Las Palmas de Gran Canaria, Canary Islands 2007.

[25] Pintaud JC, Zehdi S, Couvreur T, et al. Species delimitation in the genus Phoenix (Arecaceae) based on SSR markers, with emphasis on the identity of the date palm (Phoenix dactylifera L.) Monocots 2009; in press.

[26] Henderson S, Billote N, Pintaud JC. Genetic isolation of Cape Verde Islands Phoenix atlantica (Arecaceae) revealed by microsatellite markers. Conserv Genet 2006; 7: 213-23.

[27] Kunkel G, Kunkel MA. Flora de Gran Canaria. Arboles y arbustos arbóreos. Excmo. Cabildo Insular de Gran Canaria. Las Palmas de Gran Canaria 1974

[28] Morici C. Phoenix in the wild. Principes 1998; 42: 85-93.

[29] González-Pérez MA. Caracterización molecular de la palmera canaria (Phoenix canariensis) como base para su conservación. $\mathrm{Ph}$ D thesis, University of Las Palmas de Gran Canaria, Canary Islands 2001 .

[30] González-Pérez MA, Caujapé-Castells J, Sosa PA. Allozyme variation and structure of the canarian endemic palm tree Phoenix canariensis (Arecaceae): implications for conservation. Heredity 2004; 93: 307-15.

[31] González-Perez MA, Caujapé-Castells J, Sosa PA. Molecular evidence of hybridisation between the endemic Phoenix canariensis and the widespread $P$. dactylifera with Random Amplified Polymorphic DNA (RAPD) markers. Plant Syst Evol 2004; 247: 165-75.

[32] Ellstrand NC, Elam DR. Population genetic consequences of small population size: implications for plant conservation. Annu Rev Ecol Syst 1993; 24: 217-42.

[33] Pritchard JK, Stephens M, Donnelly P. Inference of population structure using multilocus genotype data. Genetics 2000; 155: 945 59.

[34] Belkhir K, Borsa P, Goudet J, Chikhi L, Bonhomme F. Genetix, logiciel sous WindowsTM pour la génétique des populations. CNRS UPR 9060. Laboratoire Génome et Populations, Université de Montpellier, Montpellier 1998.

[35] Rosenberg NA, Pritchard JK, Weber JL, et al. Genetic structure of human populations. Science 2002; 298: 2381-5.

[36] Reyes-Betancort JA, Wilpret de la Torre W, León Arencibia MC. El paisaje vegetal de Lanzarote a partir de fuentes escritas (siglos $\mathrm{XV}-\mathrm{XX}$ ). Estudios Canarios. Anuario del Instituto de Estudios Canarios 1999.

[37] Santana SA, Toledo RJM. Introducción y dispersión de Phoenix dactylifera en el Archipiélago Canario: elementos de discusión. Second International Symposium on Ornamental Palms and other Monocts from the Tropics. Canary Islands, Spain 1997.

[38] González-Pérez MA, Sosa PA, Batista FJ. Genetic variation and conservation of the endangered endemic Anagyris latifolia Brouss. ex Willd. (Leguminosae) from the Canary Islands. Plant Syst Evol 2009; 279: 59-68. 
[39] González-Pérez MA, Sosa PA, Rivero E, González-González EA, Naranjo A. Molecular markers reveal no genetic differentiation between Myrica rivas-martinezi and M. faya (Myricaceae). Ann Bot 2009; 103: 79-86.

[40] González-Pérez MA, Lledó L, Lexer C, et al. Genetic diversity and differentiation in natural and reintroduced populations of Bencomia exstipulata and comparisons with B. caudata (Rosaceae) in the Canary Islands: an analysis using microsatellites. Bot J Linn Soc 2009; 160: 429-41.

[41] Rieseberg LH, Ellstrand NC. What can molecular and morphological markers tell us about plant hybridisation? Crit Rev Plant Sci 1993; 12: 213-41.

(C) González-Pérez and Sosa; Licensee Bentham Open.

This is an open access article licensed under the terms of the Creative Commons Attribution Non-Commercial License (http://creativecommons.org/licenses/by$\mathrm{nc} / 3.0 /$ ) which permits unrestricted, non-commercial use, distribution and reproduction in any medium, provided the work is properly cited. 